\title{
Viabilitas benih dan pertumbuhan bibit kakao (Theobroma cacao L) pada beberapa jenis media simpan dan tingkat kelembaban
}

\author{
(Seed viability and seedling growth of Cacao (Theobroma cacao L) on different type of \\ storage media and humidity levels) \\ D. W. Tambunsaribu, S. Anwar, dan D. R. Lukiwati \\ Agroecotechnology, Faculty of Animal and Agricultural Sciences, Diponegoro University \\ Tembalang Campus, Semarang 50275 - Indonesia \\ Corresponding E-mail: diantambunsaribu@gmail.com
}

\begin{abstract}
The research aimed to study the effect of type and humidity level of storage media and their interaction on cacao seed viability and seedling growth. The experiment was arranged in a completely randomized factorial design $3 \times 4$ with three replications. The first factor was the type of storage media (P) which were control (P0), charcoal shell (P1), and sawdust (P2). The second factor was the humidity level of storage media $(\mathrm{K})$ which were control (K0), moisture content $15 \%(\mathrm{~K} 1)$, moisture content $30 \%$ (K2), moisture content 45\% (K3). Parameters observed were seeds moisture content, electrical conductivity (EC), seed germination, germination vigor, germination rate, height of seedling, leaf number of seedling, dry weight of seedling and hypothetic vigor index of seedling. Data were analyzed by anova and followed Duncan's Multiple Range Test (DMRT). The treatments of charcoal shell and sawdust gave not significant effect to cacao seed viability and seedling growth, but their interactions gave significant effect on the observed parameters. Combined use of charcoal shell storage media with humidity level of $30 \%$ gave the highest result to cacao seed viability and seedling growth after storage.

Keywords : seed viability, storage media, humidity content and cacao
\end{abstract}

\begin{abstract}
ABSTRAK
Penelitian ini bertujuan mengkaji pengaruh jenis media simpan dan tingkat kelembaban media simpan serta interaksinya terhadap viabilitas benih dan pertumbuhan bibit kakao. Penelitian ini menggunakan faktorial 3x4 dengan tiga kali ulangan berbasis Rancangan Acak Lengkap. Faktor pertama adalah jenis media simpan (P) yaitu kontrol (P0), arang sekam (P1), serbuk gergaji (P2). Faktor kedua adalah kelembaban media simpan $(\mathrm{K})$ yaitu kontrol (K0), kadar air 15\% (K1), kadar air 30\% (K2), kadar air $45 \%$ (K3). Parameter yang diamati adalah kadar air benih, daya hantar listrik, daya berkecambah, vigor kecambah, kecepatan tumbuh, tinggi tanaman, jumlah daun, berat kering bibit dan indeks vigor hipotetik bibit. Data dianalisis ragam dan dilanjutkan dengan Duncan's Multiple Range Test (DMRT). Hasil penelitian menunjukkan bahwa perlakuan arang sekam dan serbuk gergaji tidak berpengaruh terhadap viabilitas benih dan pertumbuhan bibit kakao, tetapi interaksi keduanya nyata mempengaruhi parameter yang diamati. Kombinasi penggunaan media simpan arang sekam dengan tingkat kelembaban $30 \%$ memberikan pengaruh tertinggi terhadap viabilitas benih dan pertumbuhan bibit kakao setelah penyimpanan.
\end{abstract}

Kata kunci : viablitas benih, media simpan, tingkat kelembaban dan kakao

\section{PENDAHULUAN}

Kakao (Theobroma cacao L) merupakan komoditi tanaman perkebunan yang berperan penting dalam perekonomian Indonesia, terutama dalam hal pendapatan petani dan sebagai sumber devisa Negara melalui perolehan nilai ekspor. Menurut Direktorat Jendral Perkebunan (2015), 
total produksi kakao Indonesia mencapai 661.243 ton dengan nilai ekspor sebesar US\$ 1.316.867. Permintaan kakao dunia setiap tahunnya mengalami peningkatan. Hal ini membuka peluang bagi Indonesia untuk senantiasa meningkatkan produksi dan ekspor kakao. Peningkatan produksi kakao dapat dilakukan dengan penanaman areal baru dan peremajaan. Salah satu faktor yang sangat mendukung keberhasilan dan peningkatan produksi kakao adalah tersedianya benih berkualitas dan mampu tumbuh baik di lapangan (Hayati et al., 2011).

Salah satu kendala penting dalam penyediaan benih kakao berkualitas adalah sifatnya sebagai benih rekalsitran. Benih rekalsitran tidak tahan terhadap pengeringan dan peka terhadap suhu dan kelembaban yang rendah (Sumampow, 2011). Kondisi tersebut dapat menyebabkan kerusakan benih kakao diakibatkan kontaminasi mikroba, benih berkecambah dalam penyimpanan dan kekurangan oksigen. Penurunan kadar air benih sampai di bawah kadar air kritis (12\% - 31\%) dapat menyebabkan viabilitas benih kakao menurun dengan cepat, bahkan dapat menyebabkan kematian (Esrita, 2009). Benih kakao yang telah dikeluarkan dari buahnya dan disimpan tanpa perlakuan khusus, akan cepat berkecambah dalam kurun waktu 3-4 hari (Wahyudi et al., 2008).

Penyimpanan benih rekalsitran umumnya memerlukan kisaran suhu $4-20^{\circ} \mathrm{C}$ tergantung pada spesiesnya dengan kondisi ruang berkelembaban tinggi (RH $70-90 \%$ ) (Halimursyadah, 2012). Kadar air awal yang aman untuk penyimpanan adalah sekitar sekitar 35-40\% (Rahardjo dan Hartatri, 2010).

Salah satu usaha untuk mempertahankan viabilitas dan vigor benih tetap optimal adalah dengan menyimpan benih pada wadah yang berkelembaban tinggi dengan menggunakan media simpan lembab (Syaiful et al., 2007; Sumampow, 2011). Media simpan yang dapat digunakan antara lain adalah arang sekam dan serbuk gergaji yang mampu mempertahankan kadar air benih ideal selama penyimpanan (Pratiwi et al., 2011).

Penggunaan arang sekam mampu mempertahankan daya kecambah benih kakao 8598\% dengan lama penyimpanan 3 minggu (Rahardjo, 2012). Penggunaan serbuk gergaji dapat mempertahankan daya kecambah benih kakao 93,33\% (Sumampow, 2011). Penggunaan media simpan berperan sebagai penyangga kelembaban selama penyimpanan, yaitu menyediakan air apabila benih kakao kekurangan air dan sebaliknya menyerap air apabila benih kakao berlebihan air (Rahardjo, 2012). Peran dari arang sekam padi dan serbuk gergaji juga sudah diterapkan sebagai media simpan untuk memperpanjang periode penyimpanan pada beberapa jenis benih rekalsitran. Pratiwi et al. (2011) dalam penelitiannya menyatakan penyimpanan benih lengkeng (Dimocarpus longan Lour) menggunakan media simpan arang sekam dan serbuk gergaji dapat mempertahankan kadar air masing-masing 51,66 dan 51,08\% dengan daya tumbuh benih 72,08 dan $68,75 \%$ serta lama penyimpanan 30 hari. Hasil penelitian Siswanto et al. (2013) menunjukkan jenis media simpan serbuk gergaji dan arang sekam pada saat proses penyimpanan biji dapat mempertahankan kadar air biji eboni (Diospyros celebica Bakh.) sebesar 73,46 dan $75,71 \%$ pada penyimpanan 2 minggu.

Penyimpanan benih kakao pada kadar air awal benih $26-30 \%$ pada jenis media simpan arang sekam mampu mempertahankan viabilitas benih kakao dengan daya kecambah 72,67\%. Kemampuan arang sekam menjaga kelembaban agar tetap stabil dapat dihubungkan dengan sifat kelengasan media yang tinggi yakni $9,02 \%$, sifat tersebut mempengaruhi kemampuan sekam untuk mengikat air atau uap air (Syaiful et al., 2007).

Penelitian ini bertujuan mengkaji pengaruh jenis media simpan dan tingkat kelembaban media simpan serta interaksinya terhadap viabilitas benih dan pertumbuhan bibit kakao.

\section{MATERI DAN METODE}

\section{Materi}

Penelitian telah dilaksanakan pada tanggal 27 Maret 2017 sampai dengan 23 Mei 2017 di laboratorium Fisiologi dan Pemuliaan Tanaman, Fakultas Peternakan dan Pertanian, Universitas Diponegoro, Semarang. Materi yang digunakan antara lain biji kakao, arang sekam, serbuk gergaji dan aquades. 


\section{Metode}

Penelitian dimulai dengan seleksi buah kakao yang memiliki kualitas tinggi. Buah kakao dipecah, selanjutnya biji berdaging (pulp) dikeluarkan dari buah dan dihilangkan dagingnya dengan menggumpalkan dengan air kapur 2,5\% ( $25 \mathrm{~g} / 1$ air) sekitar 30 detik. Biji dikeluarkan dari air kapur dan dicuci dengan air sampai bersih. Kemudian dilakukan pengupasan kulit ari secara manual. Selanjutnya benih direndam selama 10 menit dalam larutan fungisida. Fungisida yang digunakan adalah Delsene MX-80 dengan konsentrasi 1\% (1 g/l air). Kadar air benih kakao perlu diturunkan dengan dikering-anginkan pada tempat yang teduh.

Media simpan dikering-ovenkan pada suhu $105^{\circ} \mathrm{C}$ hingga kadar air $0 \%$. Setelah media simpan dioven dilanjutkan dengan pengaturan tingkat kelembaban sebagai sebagai berikut : 1) $100 \mathrm{~g}$ masing masing media simpan $+15 \mathrm{ml}$ air, diperoleh kadar air media simpan $\pm 15 \%$,2) 100 gam masing masing media simpan $+30 \mathrm{ml}$ air, diperoleh kadar air media simpan $\pm 30 \%$, 3) 100 gam masing masing media simpan $+45 \mathrm{ml}$ air, diperoleh kadar air media simpan $\pm 45 \%$.

Plastik polypropelen dilubangi sebelum digunakan. Kemudian setiap plastik polypropelen diisi 50 butir benih. Benih yang sudah dikemas dalam plastic dimasukkan kedalam wadah simpan stoples kotak. Setiap stoples diisi satu kantong plastic dan diberi media simpan kelembaban sebanyak $200 \mathrm{~g}$ sesuai dengan perlakuannya dan selanjutnya kotak stoples ditutup.

Parameter yang diamati adalah kadar air benih, daya hantar listrik (DHL), daya berkecambah, vigor kecambah, kecepatan tumbuh, pertumbuhan bibit meliputi tinggi tanaman, jumlah daun, berat kering dan indeks vigor hipotetik bibit.

\section{Rancangan Percobaan dan Analisis Data}

Rancangan yang digunakan dalam penelitian ini adalah Rancangan Acak Lengkap (RAL) pola faktorial $3 \times 4$ dengan tiga kali ulangan. Faktor pertama adalah jenis media simpan $(\mathrm{P})$ yaitu kontrol (tanpa media simpan) (P0), arang sekam (P1), serbuk gergaji (P2). Faktor kedua adalah kelembaban media simpan (K) yaitu kontrol (tanpa perlakuan kelembaban) (K0), kadarair 15\% (K1), kadar air 30\% (K2), kadar air $45 \%(\mathrm{~K} 3)$. Analisis data dilakukan secara statistik berdasarkan prosedur analisis sidik ragam (uji F). Apabila terdapat pengaruh perlakuan, maka dilanjutkan dengan Duncan's Multiple Range Test pada taraf $5 \%$.

\section{HASIL DAN PEMBAHASAN}

Hasil analisis ragam terhadap parameter yang diamati dapat dirangkum pada Tabel 1. Pada Tabel 1 menunjukkan adanya interaksi yang nyata pada perlakuan jenis media simpan dan tingkat

Tabel 1. Rangkuman Hasil F-Hitung Pengaruh Jenis Media Simpan dan Tingkat Kelembaban Media terhadap Viabilitas Benih Kakao

\begin{tabular}{ccccr}
\hline \hline Parameter & P & K & P x K & CV \\
\hline Kadar Air Benih (KA) & $*$ & $*$ & $*$ & $7,61 \%$ \\
Daya Hantar Listrik (DHL) & tn & tn & tn & $14,88 \%$ \\
Daya Berkecambah (DB) & tn & $*$ & $*$ & $12,98 \%$ \\
Vigor Kecambah (VK) & tn & $*$ & $*$ & $12,93 \%$ \\
Kecepatan Tumbuh (KCT) & tn & $*$ & $*$ & $14,89 \%$ \\
Tinggi Bibit (TB) & tn & tn & tn & $4,70 \%$ \\
Jumlah Daun (JD) & tn & tn & tn & $7,75 \%$ \\
Berat Kering Bibit (BKB) & tn & tn & tn & $11,84 \%$ \\
Indeks Vigor Hipotetik (IVH) & tn & tn & tn & $2,35 \%$ \\
\hline
\end{tabular}

Keterangan : P (jenis media simpan), K (tingkat kelembaban media), CV (Koefisien variasi),

* (nyata berpengaruh), tn (nyata tidak berpengaruh). 
kelembaban terhadap kadar air benih, daya berkecambah, vigor kecambah dan kecepatan tumbuh.

\section{Kadar Air Benih}

Tingginya kadar air benih pada perlakuan Kontrol (P0) (Tabel 2) yang diberikan perlakuan kelembaban diakibatkan oleh tidak adanya media simpan yang berperan sebagai penyangga kelembaban. Rahardjo (2012) menyatakan penggunaan media simpan sebagai penyangga kelembaban akan menyediakan air ketika benih kakao kekurangan air dan sebaliknya menyerap air apabila benih kakao berlebihan air.

Penggunaan arang sekam dengan tingkat kelembaban $45 \%$ mampu mempertahankan kadar air tetap tinggi. Hal ini menunjukkan media simpan arang sekam dengan kelembaban 45\% memiliki kemampuan lebih tinggi dibandingkan kelembaban kontrol dan kelembaban 15\% untuk mempertahankan kadar airnya agar tetap sesuai dengan standarnya yaitu $30-40 \%$ (Permentan, 2013). Penggunaan media simpan serbuk gergaji pada kelembaban 45\% menghasilkan nilai kadar air tertinggi dibandingkan perlakuan lainnya. Namun kadar air benih 44,32\% setelah penyimpanan, merupakan nilai kadar air yang terlalu tinggi dan melampaui standarnya, sehingga kadar air 36,36\% pada kelembaban 30\% merupakan nilai yang lebih optimal. Pratiwi et al. (2011) menyatakan serbuk gergaji dan arang sekam memiliki kemampuan untuk mempertahankan kadar air benih tinggi selama penyimpanan.

Perlakuan tingkat kelembaban kontrol pada media simpan serbuk gergaji menghasilkan kadar air benih $23,20 \%$ nyata lebih rendah $(\mathrm{P}<0,05)$ dibandingkan jenis media simpan lainnya. Perlakuan tanpa kelembaban (kontrol) pada masing-masing media simpan menyebabkan terjadinya penurunan kadar air benih dan berada pada kadar air kritisnya 12\%-31\% (Erista, 2009). Benih bersifat hygoskopis dan selalu berusaha

Tabel 2. Hasil Uji Lanjut DMRT Pengaruh Jenis Media Simpan dan Tingkat Kelembaban Media terhadap Viabilitas Benih Kakao

\begin{tabular}{c|ccccc}
\hline Perlakuan & Kadar air & Daya Berkecambah & Vigor Kecambah & Kecepatan Tumbuh \\
\hline P0 & $36,75 \mathrm{a}$ & $76,00 \mathrm{a}$ & $72,33 \mathrm{a}$ & $4,55 \mathrm{a}$ \\
P1 & $33,03 \mathrm{~b}$ & $76,67 \mathrm{a}$ & $73,33 \mathrm{a}$ & $5,04 \mathrm{a}$ \\
P2 & $34,30 \mathrm{~b}$ & $69,00 \mathrm{a}$ & $67,00 \mathrm{a}$ & $5,08 \mathrm{a}$ \\
K0 & $27,92 \mathrm{c}$ & $65,78 \mathrm{~b}$ & $61,78 \mathrm{~b}$ & $4,27 \mathrm{~b}$ \\
K1 & $34,38 \mathrm{~b}$ & $77,78 \mathrm{a}$ & $71,56 \mathrm{a}$ & $5,24 \mathrm{a}$ \\
K2 & $36,51 \mathrm{~b}$ & $77,78 \mathrm{a}$ & $74,67 \mathrm{a}$ & $5,33 \mathrm{a}$ \\
K3 & $39,96 \mathrm{a}$ & $74,22 \mathrm{a} \mathrm{b}$ & $75,56 \mathrm{a}$ & $4,71 \mathrm{ab}$ \\
P0K0 & $30,47 \mathrm{e}$ & $77,33 \mathrm{a} \mathrm{b}$ & $73,33 \mathrm{abc}$ & $5,20 \mathrm{ab}$ \\
P0K1 & $38,29 \mathrm{bc}$ & $81,33 \mathrm{a}$ & $74,67 \mathrm{abc}$ & $5,44 \mathrm{a}$ \\
P0K2 & $39,42 \mathrm{~b}$ & $66,67 \mathrm{abc}$ & $65,33 \mathrm{abcd}$ & $4,50 \mathrm{abcd}$ \\
P0K3 & $38,80 \mathrm{~b}$ & $78,67 \mathrm{ab}$ & $76,00 \mathrm{abc}$ & $5,02 \mathrm{abc}$ \\
P1K0 & $30,09 \mathrm{e}$ & $57,33 \mathrm{c}$ & $50,67 \mathrm{~d}$ & $3,62 \mathrm{~d}$ \\
P1K1 & $31,51 \mathrm{e}$ & $84,00 \mathrm{a}$ & $81,33 \mathrm{a}$ & $5,70 \mathrm{a}$ \\
P1K2 & $33,76 \mathrm{cde}$ & $82,67 \mathrm{a}$ & $82,67 \mathrm{a}$ & $5,64 \mathrm{a}$ \\
P1K3 & $36,76 \mathrm{bcd}$ & $82,67 \mathrm{a}$ & $78,67 \mathrm{ab}$ & $5,35 \mathrm{ab}$ \\
P2K0 & $23,20 \mathrm{f}$ & $62,67 \mathrm{bc}$ & $61,33 \mathrm{bcd}$ & $4,01 \mathrm{bcd}$ \\
P2K1 & $33,32 \mathrm{de}$ & $68,00 \mathrm{abc}$ & $68,00 \mathrm{abc}$ & $4,58 \mathrm{abcd}$ \\
P2K2 & $36,36 \mathrm{bcd}$ & $84,00 \mathrm{a}$ & $78,67 \mathrm{ab}$ & $5,85 \mathrm{a}$ \\
P2K3 & $44,32 \mathrm{a}$ & $61,33 \mathrm{bc}$ & $60,00 \mathrm{~cd}$ & $3,77 \mathrm{~cd}$ \\
\hline
\end{tabular}

Keterangan : Angka yang diikuti huruf berbeda pada kolom yang sama pada masing-masing perlakuan dan interaksi menunjukkan perbedaan nyata $(\mathrm{P}<0,05), \mathrm{P} 0$ (kontrol), P1 (arang sekam), P2 (serbuk gergaji), K0 (kontrol), K1 (kelembaban 15\%), K2 (kelembaban 30\%), K3 (kelembaban 45\%). 
mencapai kondisi keseimbangan dengan lingkungannya (Sutopo, 2002). Sehingga ketika kelembaban udara ditempat penyimpanan rendah maka benih akan berusaha meningkatkan kelembaban udara disekitarnya dengan menguapkan air yang ada didalam benih sehingga kadar air didalam benih menurun (Hayati et al., 2011).

Secara umum tingkat kelembaban 15\%, 30\% dan 45\% masih mampu mempertahankan kadar air benih tetap tinggi yaitu pada kisaran $30-40 \%$. Hal ini disebabkan oleh kondisi kelembaban nisbi ruang simpan yang juga tinggi yaitu $71,32 \%$. Benih rekalsitran membutuhkan ruang berkelembaban tinggi (RH 70 - 90\%) untuk mempertahankan kadar airnya (Halimursyadah, 2012).

\section{Daya Hantar Listrik}

Hasil analisis ragam pada Tabel 1 menunjukkan bahwa perlakuan media simpan dan tingkat kelembaban tidak berpengaruh nyata terhadap DHL benih kakao. Hal ini disebabkan kadar air benih kakao masih tinggi setelah penyimpanan, sehingga kerusakan integritas membran belum terjadi. Rahayu et al. (2014) menyatakan nilai DHL benih kakao akan mengalami peningkatan sejalan dengan menurunnya kadar air benih. Sehingga dengan kadar air benih yang masih tinggi (30-40\%) pada masing-masing perlakuan, menyebabkan pengaruh kedua perlakuan tidak nyata.

\section{Daya Berkecambah}

Salah satu syarat benih dikatakan memiliki kualitas baik apabila daya kecambahnya mampu mencapai minimal 80\% (Permentan, 2013). Perlakuan media simpan (kontrol) pada tingkat kelembaban 15\% mampu mempertahankan daya kecambah tetap tinggi yaitu 81,33\% (Tabel 2). Tingginya daya kecambah pada kontrol dipengaruhi oleh kadar air benih yang masih tinggi setelah penyimpanan. Kadar air benih kakao berperan penting untuk mempertahankan daya kecambah benih kakao (Syaiful et al., 2007). Kadar air tinggi akan membantu mempertahankan struktur sel benih rekalsitran (Halimursyadah, 2007). Pada media simpan arang sekam, daya berkecambah cenderung konstan, kecuali pada tingkat kelembaban 0\% dengan daya kecambah 57,33\% yang diakibatkan oleh kadar air berada pada level kritis. Hal ini menunjukkan media simpan arang sekam mampu mempertahankan kelembaban tetap stabil. Kemampuan arang sekam menjaga kelembaban agar tetap stabil untuk penyimpanan dapat dihubungkan dengan sifat lengas media yang tinggi yakni 9,02\% (Syaiful et al., 2007). Sifat tersebut mempengaruhi kemampuan arang sekam mengikat air atau uap air. Perlakuan serbuk gergaji memberikan pengaruh terbaik pada tingkat kelembaban 30\% dengan daya berkecambah $84 \%$. Hal ini berhubungan dengan kadar air benih yang masih tinggi setelah penyimpanan. Menurut Siswanto et al. (2013) serbuk gergaji mampu mempertahankan kadar air benih sehingga tidak menurunkan daya kecambah benih saat ditanam. Syaiful et al. (2007) menyatakan kadar air benih sangat berpengaruh terhadap tinggi rendahnya daya berkecambah benih kakao.

Kelembaban $15 \%$, $30 \%$ dan $45 \%$ pada masing-masing media simpan memberikan pengaruh tidak nyata terhadap daya kecambah benih kakao. Hal ini disebabkan oleh kadar air benih yang masih tinggi pada masing-masing perlakuan setelah penyimpanan. Menurut Sutopo (2002 kandungan air benih menjadi salah satu faktor internal yang mempengaruhi viabilitas benih dalam penyimpanan. Halimursyadah (2007) juga menyatakan bahwa kelembaban berpengaruh nyata terhadap tolak ukur kadar air, daya berkecambah, kecepatan tumbuh, dan indeks vigor. Meskipun tidak berpengaruh nyata, tingkat kelembaban 15\% dan 30\% memiliki kemampuan lebih baik untuk mempertahankan daya kecambah tetap tinggi diatas $80 \%$. Daya kecambah lebih tinggi diduga karena pada kondisi tersebutlah tercapai kesetimbangan antara kadar air benih dan kelembaban udara ruang simpan. Kondisi dengan kelembaban yang relatif tinggi sesuai dengan kondisi simpan yang dikehendaki oleh benih rekalsitran dalam mempertahankan viabilitas dan vigornya (Hayati et al., 2011).

\section{Vigor Kecambah}

Perlakuan tanpa media simpan (kontrol) menunjukkan tidak adanya pengaruh signifikan 
pada masing-masing tingkat kelembaban (Tabel 2). Hal ini diakibatkan oleh tidak adanya media simpan yang berperan mengontrol kelembaban dilingkungan penyimpanan. Jadi ketika diberikan tingkat kelembaban yang berbeda tidak akan menghasilkan pengaruh berbeda terhadap vigor kecambah. Perlakuan arang sekam dengan kelembaban $15 \%$ dan $30 \%$ mampu mempertahankan vigor benih kakao tetap tinggi selama penyimpanan. Syaiful et al. (2007) menyatakan penggunaan media simpan arang sekam dan serbuk gergaji dengan kelembaban tepat (15\%-30\%) mampu mengurangi respirasi. Laju respirasi rendah dapat menghambat penurunan kualitas benih dan vigor benih dapat dipertahankan tetap tinggi. Perlakuan serbuk gergaji pada kelembaban $30 \%$ memberikan pengaruh nyata lebih tinggi dibandingkan kelembaban $45 \%$. Hal ini menunjukkan kelembaban terlalu tinggi (45\%) dapat menyebabkan terjadinya penurunan kualitas benih.

Selain kelembaban $45 \%$ pada media simpan serbuk gergaji, tingkat kelembaban 15\%, 30\% dan $45 \%$ pada masing-masing media simpan tidak memberikan pengaruh nyata. Tingginya kadar air benih setelah penyimpanan merupakan faktor penyebabnya. Dengan kadar air tinggi, benih akan mampu memertahankan vigornya tetap tinggi karena air berperan dalam menjaga stabilitas membran dan makromolekul benih (Halimursyadah, 2007). Menurut Syaiful et al. (2007) salah satu usaha untuk mempertahankan viabilitas dan vigor benih tetap tinggi adalah dengan menyimpan benih pada wadah berkelembaban tinggi dengan menggunakan media simpan lembab.

\section{Kecepatan Tumbuh}

Data pada Tabel 2 menunjukkan perlakuan jenis media dan tingkat kelembaban media memberikan pengaruh sama terhadap kecepatan tumbuh dan daya kecambah. Menurut Rahayu et al. (2014) tinggi rendahnya kecepatan tumbuh kecambah berhubungan dengan tinggi rendahnya daya kecambah. Semakin tinggi daya kecambah maka semakin tinggi juga kecepatan tumbuh demikian sebaliknya. Sehingga tinggi rendahnya kecepatan tumbuh dipengaruhi oleh faktor sama yang mempengaruhi daya kecambah benih kakao yaitu kadar air benih.

Lodong et al. (2015) menyatakan viabilitas benih nangka sangat dipengaruhi oleh kadar air, khususnya daya berkecambah dan kecepatan tumbuh yang sangat berkaitan erat dengan kadar air benih. Kadar air tinggi mampu mempertahankan struktur sel benih kakao tetap baik, jadi ketika ditanam benih akan dengan cepat tumbuh. Syaiful et al. (2007) menyatakan kecepatan tumbuh tetap tinggi karena benih selama penyimpanan dapat mempertahankan cadangan makanan dan dapat menekan perombakan akibat proses respirasi, sehingga pada saat dikecambahkan memiliki energi yang besar untuk cepat muncul. Siswanto et al. (2013) dalam penelitiannya tentang biji eboni (Diospyros celebica Bakh.) menyatakan bahwa penggunaan media simpan dengan kadar air yang tepat dapat mengurangi laju respirasi.

Halimursyadah (2007) menyatakan kecepatan tumbuh dan indeks vigor dipengaruhi oleh tingkat kelembaban. Adanya kelembaban akan mempertahankan kadar air benih kakao tetap tinggi. Air adalah faktor penting dalam mempertahankan viabilitas dan vigor benih rekalsitran selama penyimpanan. Kadar air yang terjaga selama proses penyimpanan menekan terjadinya gangguan metabolisme, sehingga kemunduran benih dapat diperlambat dan meningkatkan kecepatan tumbuh kecambah (Syaiful et al., 2007). Tidak adanya pengaruh nyata pada perlakuan kelembaban kontrol, 15\%, $30 \%$ dan $45 \%$ pada masing-masing media simpan disebabkan oleh tingginya kadar air benih.

\section{Pertumbuhan Bibit Kakao Umur 28 Hari}

Tabel 1 menunjukkan bahwa perlakuan jenis media simpan dan tingkat kelembaban tidak memberikan pengaruh nyata terhadap pertumbuhan bibit kakao meliputi tinggi bibit, jumlah daun dan berat kering bibit.

Tidak adanya interaksi terhadap pertumbuhan tinggi tanaman dan jumlah daun diduga disebabkan periode simpan dan pengamatan pertumbuhan bibit kakao pada umur yang singkat. Hasid (2008) menyatakan penyimpanan benih rekalsitran kakao dalam ruang bersuhu kamar selama satu bulan, tidak menyebabkan banyak perubahan keragaan benih bahkan pada perlakuan 
kontrol. Selain itu, kualitas mutu genetis dan fisiologis benih yang digunakan secara tidak langsung mampu mempertahankan pertumbuhan tanaman tetap tinggi (Rahardjo, 2011). Menurut Rahardjo dan Hartatri (2010) penggunaan media simpan hanya membantu sebagai bahan penyangga, apabila kondisi lembab akan menyerap uap air dan bila kondisi kering akan melepaskan air, dengan demikian tidak berdampak secara langsung terhadap pertumbuhan bibit kakao.

Perlakuan media simpan dan tingkat kelembaban tidak berpengaruh terhadap berat kering bibit disebabkan oleh nilai daya kecambah yang relatif sama antar perlakuan. Lodong et al. (2015) menyatakan bobot kering bibit sangat berhubungan dengan daya berkecambah dimana semakin tinggi daya berkecambah, pertumbuhan bibit akan semakin cepat, dengan demikian menghasilkan bobot kering yang lebih berat. Sehingga apabila daya kecambah relatif sama, maka akan memberikan pengaruh yang sama terhadap berat kering bibit.

Tidak adanya interaksi dari masing masing perlakuan terhadap ketiga parameter pertumbuhan bibit kakao juga disebabkan kadar air benih yang tinggi yaitu pada kisaran normal 30-40\% (Permentan, 2013). Hasid (2009) menyatakan apabila kondisi kadar air benih mampu dipertahankan tetap optimal setelah penyimpanan maka kerusakan benih secara fisik, fisiologi, biokimiawi, dan seluler dapat dihindari. Selain itu daya berkecambah dan kecepatan tumbuh yang tinggi secara tidak langsung akan mempengaruhi pertumbuhan bibit selanjutnya, karena bibit akan segera mengabsorbsi makanannya sendiri dari lingkungan tumbuhnya melalui organ-organ vegetatif (Lodong et al., 2015).

\section{Indeks Vigor Hipotetik}

Data pada Tabel 1 menunjukkan perlakuan jenis media simpan dan tingkat kelembaban tidak memberikan pengaruh nyata terhadap IVH. Hal ini disebabkan oleh pengamatan pertumbuhan bibit kakao pada umur yang terlalu singkat yaitu 28 HST. Selain itu nilai daya kecambah yang relatif sama menjadi faktor pendukung yang menyebabkan tidak adanya interaksi antar perlakuan. Nilai IVH yang diperoleh tidak terlepas dari viabilitas benih. Immawati et al. (2013) menyatakan benih dengan viabilitas tinggi akan menghasilkan nilai vigor hipotetik yang tinggi pula, dikarenakan vigor hipotetik menggambarkan kemampuan tumbuh benih menjadi bibit. Benih dengan nilai kecambah tinggi juga akan mampu tumbuh menjadi bibit dengan optimal.

\section{KESIMPULAN}

Berdasarkan hasil penelitian dapat disimpulkan bahwa penggunaan media simpan arang sekam dan serbuk gergaji tidak berpengaruh terhadap viabilitas benih dan pertumbuhan bibit kakao. Tingkat kelembaban media simpan 30\% memberikan pengaruh tertinggi terhadap viabilitas benih dan pertumbuhan bibit kakao. Kombinasi penggunaan media simpan arang sekam dengan tingkat kelembaban 30\% memberikan pengaruh tertinggi terhadap viabilitas benih dan pertumbuhan bibit kakao setelah penyimpanan.

\section{DAFTAR PUSTAKA}

Direktorat Jendral Perkebunan. 2015. Statistik Perkebunan Indonesia 2014-2016. http://ditjenbun.pertanian.go.id.

Esrita. 2009. Studi anatomi embrio benih kakao pada beberapa kadar air benih dan tingkat pengeringan. Jurnal Agonomi. 13(1): 1-5.

Halimursyadah. 2007. Studi Penanganan Benih Rekalsitran (Avicennia marina (Forsk.) Vierh. : Desikasi, Penyimpanan dan Viabilitas.Tesis. Institut Pertanian Bogor, Bogor.

Halimursyadah. 2012. Pengaruh kondisi simpan terhadap viabilitas dan vigor benih Avicennia marina (Forsk.) Vierh. Pada beberapa periode simpan. Jurnal Agotropika. 17(2):4351.

Hasid, R. 2008. Keragaan dan mutu fisiologis benih rekalsitran kakao (Theobroma cocao L.) pada berbagai kondisi penyimpanan. Agriplus. 18(1):38-43.

Hasid, R. 2009. Laju penurunan kadar air benih 
rekalsitran kakao (Theobroma cacao L.) pada berbagai kondisi penyimpanan. Agriplus. 19(1):40-44.

Hayati, R., Z. A. Pian dan Syahril. 2011. Pengaruh tingkat kemasakan buah dan cara penyimpanan terhadap viabilitas dan vigor benih kakao (Theobroma cacao L.). J. Floratek. 6:114-123.

Immawati, D. R., S. Purwanti dan D. Prajitno. Daya simpan benih kedelai hitam (Glycine $\max (\mathrm{L})$ Merrill) hasil tumpangsari dengan sorgum manis (Shorgum bicolor (L) Moench). Vegetalika. 2(4):25-34.

Lodong, O., Y. Tambing dan Adrianton. 2015. Peranan kemasan dan media simpan terhadap ketahanan viabilitas dan vigor benih nangka (Artocarpus heterophyllus Lamk) kultivar tulo-5 selama penyimpanan. e-J. Agrotekbis. 3(3): 303-3015.

Peraturan Menteri Pertanian NOMOR 90/Permentan/OT.140/9/2013. Standar Operasional Prosedur Penetapan Kebun Sumber Benih, Sertifikasi Benih, dan Evaluasi Kebun Sumber Benih Tanaman Kakao (Theobroma cacao L.).

Pratiwi, R. D., R. Rabaniyah dan A. Purwantoro. 2011. Pengaruh jenis dan kadar air media simpan terhadap viabilitas benih lengkeng (Dimocarpus longan Lour). J.Vegetalika. 1(2):1-6.

Rahardjo, P. dan D. F. S. Hartatri. 2010. Penggunaan acrylic acid sodium polymer dalam upaya mempertahankan viabilitas benih kakao (Theobroma cacao L.). Pelita Perkebunan. 26(2):83-93.
Rahardjo, P. 2011. Menghasilkan Benih dan Bibit Kakao Unggul. Penebar Swadaya, Jakarta.

Rahardjo, P. 2012. Pengaruh pemberian abu sekam padi sebagai bahan desikan pada penyimpanan benih terhadap daya tumbuh dan pertumbuhan bibit kakao. Pelita Perkebunan. 28(2):91-99.

Rahayu, A., T. Hardiyati dan P. Hidayat. 2014. Pengaruh polyethylene glycol 6000 dan lama penyimpanan terhadap mutu benih kakao (Theobroma cacao L.). Pelita Perkebunan. 30(1):15-24.

Siswanto, H., T. Nurhidayati dan Trimanto. 2013. Pengaruh konsentrasi natrium benzoat dan media simpan terhadap kualitas biji eboni (Diospyros celebica Bakh.) selama masa simpan. e-J. Institut Teknologi Sepuluh November. 1-7.

Sumampow, D. M. F. 2011. Viabilitas benih kakao (Theobroma cacao L.) pada media simpan serbuk gergaji. Soil Environment. 8(3):102105.

Syaiful, S. A., M. A. Ishak, dan Jusriana. 2007. Viabilitas benih kakao (Theobroma cacao L.) pada berbagai tingkat kadar air benih dan media simpan benih. J. Agivigor. 6(3):243251.

Sutopo, L. 2002. Teknologi Benih. PT Rajagafindo Persada, Jakarta.

Wahyudi, T., T. R. Panggabean dan Pujiyanto. 2008. Panduan Lengkap Kakao. Penebar Swadaya, Jakarta. 